\title{
Evaluation of Customer Relationship Management in a Teaching Hospital
}

\author{
${ }^{1}$ Fereshteh Farzianpour, ${ }^{2}$ Leila Godarzi, \\ ${ }^{1}$ Amin Torabipoor Hamedani, ${ }^{1}$ Roholah Askari and ${ }^{3}$ Sayed Shahab Hosseini \\ ${ }^{1}$ Departmet of Health Management and Economics, \\ School of Public Health, Tehran University of Medical Sciences, Tehran, Iran \\ ${ }^{2}$ Departments of Biology, Faculty of Sciences, Alzahra University, Vanak, Tehran, Iran \\ ${ }^{3}$ Department Management, Faculty of Management, Tehran University, Iran
}

Received 2012-03-02, Revised 2013-04-15; Accepted 2013-04-2

\begin{abstract}
Communication between individuals has a vital role in human being's life, specially their professional. In medical practice it is a certain and economical way recognize the patient's problems and identify them. It is necessary to communicate with patients suffering mental or physical problems to be able to look after them. An analyticaldescriptive cross-sectional study was conducted. The population under study consisted of the patients being discharged from a teaching hospital during a 15-day period. The patients were interviewed at discharge time. A sample of 100 patients was included in the study. The samples were selected through simple random method. The data were gathered using a valid questionnaire which was approved by the experts in this field. The reliability of the questionnaire was determined to be $82 \%$ using the method test- retest and Cronbach's alpha test. Fisher test and $\mathrm{T}$ test analyses were carried out to determine the association between each variable and satisfaction status. patients' satisfaction with hospital services concerning medical, nursing, paraclinical and discharge services, section and Patients' general satisfaction with hospital services were in general, 13.2, 45, 20.1, 7.6 and $2.8 \%$ were quiet satisfied, satisfied, rather satisfied and quiet dissatisfied respectively. The statisticalanalytical test showed that there was a significant statistical relation between the age of the patients and the degree of their satisfaction with the nursing staff treatment $(p=0.012)$ and that of service staff $(p=0.009)$.
\end{abstract}

Keywords: Teaching Hospital, Analytical-Descriptive, Cross-Sectional, Cronbach's Alpha Test

\section{INTRODUCTION}

Communication is a dynamic process between humans which is used to produce effects, gain mutual support and what is necessary in order to be healthy and continue living (Farzianpour and Godarzi, 2010). In fact, life without communication would be deadly and impossible to continue (Schoenfelder et al., 2010). Communication between individuals has a vital role in human beings, life, specially their professional life (Mpinga and Chastonay, 2011). In medical practice it is a certain and economical way recognize the patient's problems and identify them. It is necessary to communicate with patients suffering mental or physical problems to be able to look after them. Through communication patients' problems can be identified and so suitable care plans can be made to remove those (Saila et al., 2008). It is through communication that patients can express their feeling of pain and illness and nurses can become aware of the patients feelings, needs and problems and so can make a plan to look after them. In fact communication is part of treatment plan (Anastasios et al., 2004). The ability to communicate with the patients is one of the necessities of nursing and medical practice (Farzianpour et al., 2012).

Through communication with patients, nurses can recognize their needs and problems and design a treatment plan. Through communication, patients can

Corresponding Author: Fereshteh Farzianpour, Departmet of Health Management and Economics, School of Public Health, Tehran University of Medical Sciences, Tehran, Iran 
feel secure and trust the treatment team (Stevens et al., 2006). It is true that all professions and practices need communication skills, but none of them needs it as much as nursing does because nursing is a practice in which implementing duties depends on communication. Nurses who have the ability to communicate with individual patients are better able to promote the patient's health (Hung et al., 2010). To communicate with patients satisfactorily, physicians need to know what effect the patient's body has on their mind and behavior. Therefore, they should pay attention to the patients considering both their physical and mental status in order to achieve a comprehensive treatment (Jangland et al., 2009). Research on patient's expectation of his/her physician makes it possible to use a more fundamental approach to understand the relationship between the patient and the physician and causes the decisions made regarding the patients not to be absolutely dependent on the physician but the patient's expectation to be considered as well. On the other hand, the physician's time limitation and external pressure to visit more patients in a more limited time make it difficult for the doctor to meet the patient's expectation (Farzianpour et al., 2011a).

It should be pointed out that the patients' needs and expectations and their experiences with receiving health and treatment services affect their general satisfaction (Farzianpour et al., 2011b). Satisfaction means the feeling of patients about quality and quantity of treatment services offered to them in health and treatment centers and this feeling is created through the process of treatment and relationship between the patients and the medical team, especially the physicians (Boyer et al., 2009; Farzianpour et al., 2011c).

Studies indicate that listening to the client's complaint, removing the cause of the complaint and following up to see if the client is satisfied (the feedback) constitute 90,7 and $3 \%$ of the medical team's responsibility respectively (Hekkert et al., 2009).

The studies conducted regarding the relationship between the patient and the physicians indicate the fact that this relationship is the basic indicator of the medical performance: Only $23 \%$ of the patients had the opportunity to complete their words while talking to their physician. Out of $51 \%$ of cases considering physicianpatient relationship only in one case the patient can express his or her whole complaint. In $94 \%$ of cases the patient is interrupted by the physician or other members of the medical team.
Out of 50 visits 34 patients are interrupted by the physician before the patient expresses his/her primary worries (Sherlaw-Johnson et al., 2008). Patient relationship management can be defined as a patientcentered way to create a better relationship in order to have a good understanding of patients' needs and cause them to have the highest degree of satisfaction with the course of treatment (Sherlaw-Johnson et al., 2008). Through a strategic method the clients and the target market can be identified and through planning the services of health and treatment centers patient can be helped to meet their needs and so to feel satisfied (Sherlaw-Johnson et al., 2008). Patient relationship management is an attitude associated with technical and organizational strategic changes through which a health organization tries to manage its business in a better way considering patients' satisfaction (Sherlaw-Johnson et al., 2008). The aim of the present study is to evaluate the state of patient's relationship management and its different aspects in a teaching hospital affiliated with Tehran University of medical sciences.

\section{MATERIALS AND METHODS}

An analytical-descriptive cross-sectional study was conducted. The population under study consisted of the patients being discharged from a teaching hospital during a 15-day period. The patients were interviewed at discharge time. The questionnaires were filled out by the researcher. Using the formula for determining the sample size, a sample of 100 patients was included in the study. The samples were selected through simple random method. The data were gathered using a valid questionnaire which was approved by the experts in this field. The reliability of the questionnaire was determined to be $82 \%$ using the method test-retest and Cronbach's alpha test. Questionnaire consisted of 57 questions: 11 questions on demographic characteristics and 46 on patient's satisfaction considering medical nursing and nutrition services, environment, facilities, admit ion, discharge and service staff's treatment.

The questions were considered to adequately explore the true state of patient satisfaction. An expert committee approved these questions as relevant to measure satisfaction, confirming their validity. At the end a descriptive analysis of all variables was conducted, calculating frequency distributions and means, standard 
deviations and percentiles as appropriate. Fisher test and $\mathrm{T}$ test analyses were carried out to determine the association between each variable and satisfaction status. SPSS and Excel software were used for the data analysis.

\section{RESULTS}

Findings of the study, considering patient's demographic characteristics.

Out of 100 patients selected $48(48 \%)$ were male and $52(52 \%)$ were female. 242318,16 and $13 \%$ were in age groups 30 to 40,60 and beyond, 20 to 30,40 to 50 and 50 to 60 respectively.

Concerning education $16 \%$ were illiterate, 36, 30, 7 and $11 \%$ held primary or secondary school certificate, a high school diploma, upper diploma, B.A. degree respectively. Regarding employment $26 \%$ were jobless, $39 \%$ had a job and $35 \%$ house wives.

Concertinaing marital status $73 \%$ were married and $26 \%$ single. $80 \%$ of the patients had insurance coverage of a kind of medical insurance company (39\% by social security, $32.1 \%$ by treatment services, $8.6 \%$ by armed forces, $6.2 \%$ by Emdad committee (a charity organization which offers financial aid to the poor) and the rest by other companies.

Most of the patients (41\%) were hospitalized 5-10 days. Concerning hospitalization background 38\% had previously been hospitalized at this hospital and the others didn't have any hospitalization background. 96\% lived in urban areas and $4 \%$ in rural ones.

Findings related to absolute and relative frequency of patients' satisfaction with the way the hospital personnel treat them.

Concerning patients' satisfaction with the way the doorkeeper and receptionist treat them, 9, 63, 15 and $12 \%$ were completely satisfied, satisfied, rather satisfied and dissatisfied respectively. Regarding guiding the patients when they enter the hospital 14, 57, 21 and $6 \%$ were completely satisfied, satisfied, rather satisfied and dissatisfied respectively. With respect to the way the receptionist personnel treat them $6,69,22$ and $1 \%$ were completely satisfied, satisfied, rather satisfied and dissatisfied respectively. Concerning patients' satisfaction with the interval between file formation and hospitalization 9, 64, 22 and $2 \%$ were completely satisfied, satisfied, rather satisfied and dissatisfied respectively. With regard to the length of the time they wait until they are visited by the doctor $21,55,19$ and $5 \%$ were completely satisfied, satisfied, rather satisfied and dissatisfied respectively. Concerning the way doctors behaves towards them $35,45,15,3$ s and $2 \%$ were completely satisfied, satisfied, rather satisfied and dissatisfied respectively. Regarding the way nonmedical personnel treat them 10, 59, 25, 4, 2\% were completely satisfied, satisfied, rather satisfied and dissatisfied respectively (Table 1-5).

Based on Table 1-5 the average of the degree of patients' satisfaction with any section is as follows: $18.1 \%$ were completely satisfied, $57.7 \%$ satisfied, $19.6 \%$ rather satisfied $3.5 \%$ dissatisfied and $1.5 \%$ completely dissatisfied considering. Medical staff services. $10.2 \%$ completely satisfied, $56.8 \%$ satisfied, $26.3 \%$ rather satisfied, $5.9 \%$ dissatisfied and $2 \%$ completely dissatisfied. Considering medical nursing services. As to par clinic services including clinical laboratory and imaging 4.2\% completely satisfied, $46.2 \%$ satisfied, $8.6 \%$ rather satisfied and $2 \%$ dissatisfied considering hospital services staff $10.7 \%$ completely satisfied, $47 \%$ satisfied, $17.3 \%$ rather satisfied $14.7 \%$ dissatisfied and 5\% completely dissatisfied. Considering discharge unit services23, 26.2, 29, 12 and 3\%were quiet satisfied, satisfied, rather satisfied, dissatisfied and quiet dissatisfied respectively. In general, the degree of patients' satisfaction with medical and nursing services more than that with other services (Fig. 1).

Patients' general satisfaction with hospital services is shown in Fig. 2. In general, 13.2, 45, 20.1, 7.6 and 28\% were quiet satisfied, satisfied, rather satisfied and quiet dissatisfied respectively.

In the present study the patients were asked if they liked to choose the hospital in the future, if needed. The answers indicated 57\%would choose the hospital and $14 \%$ another one.

The findings of the study also showed that considering different wards of the hospital, the highest degree of patients' satisfaction was with transplant ward (90\%) and the lowest (20\%) with women internal ward (Table 6).

The statistical-analytical test showed that there is a significant statistical relation between the age of the patients and the degree of their satisfaction with the nursing staff treatment $(\mathrm{p}=0.012)$ and that of service $\operatorname{staff}(\mathrm{p}=0.009)$. 
Fereshteh Farzianpour et al. / American Journal of Applied Sciences, 10 (4): 344-352, 2013

Table 1. Absolute and relative frequency distribution concerning the degree of patient's satisfaction based on different hospital services Status satisfaction

\begin{tabular}{|c|c|c|c|c|c|}
\hline $\begin{array}{l}\text { hospital services } \\
\text { A-medical staff }\end{array}$ & $\begin{array}{l}\text { Completely } \\
\text { dissatisfied }\end{array}$ & Dissatisfied & $\begin{array}{l}\text { Fairly } \\
\text { satisfied }\end{array}$ & Satisfied & $\begin{array}{l}\text { Completely } \\
\text { satisfied }\end{array}$ \\
\hline The way medical staff (except & 2 & 4 & 25 & 59 & 10 \\
\hline $\begin{array}{l}\text { the physician) treat towards } \\
\text { the patients }\end{array}$ & 2 & 4 & 25 & 59 & 10 \\
\hline The length of the time & - & 5 & 19 & 55 & 21 \\
\hline $\begin{array}{l}\text { needed for the physician } \\
\text { to visit the patient }\end{array}$ & - & 5 & 19 & 55 & 21 \\
\hline The way the physician & 2 & 3 & 15 & 45 & 35 \\
\hline behaves the patient & 2 & 3 & 15 & 45 & 35 \\
\hline The physician's mastery & 1 & 2 & 14 & 51 & 32 \\
\hline and experience & 1 & 2 & 14 & 51 & 32 \\
\hline The physician's giving & - & 4 & 22 & 59 & 15 \\
\hline information to the patient & - & 4 & 22 & 59 & 15 \\
\hline The physician's recommendations & - & 6 & 25 & 62 & 7 \\
\hline before discharge & - & 6 & 25 & 62 & 7 \\
\hline Listening to the patient talking & - & 2 & 13 & 71 & 13 \\
\hline about his/her illness & - & 2 & 13 & 71 & 13 \\
\hline General behavior of the & - & 2 & 17 & 58 & 22 \\
\hline hospital's physicians & - & 2 & 17 & 58 & 22 \\
\hline The physician's availability & - & 4 & 27 & 60 & 8 \\
\hline when there is a need & - & 4 & 27 & 60 & 8 \\
\hline Total means & $1 / 5$ & $3 / 5$ & $19 / 6$ & $57 / 7$ & $18 / 1$ \\
\hline
\end{tabular}

Table 2. Absolute and relative frequency distribution concerning the degree of patient's satisfaction based on different hospital services (Nursing staff)

\begin{tabular}{|c|c|c|c|c|c|}
\hline $\begin{array}{l}\text { Satisfaction status hospital services } \\
\text { B-Nursing staff }\end{array}$ & $\begin{array}{l}\text { Completely } \\
\text { dissatisfied }\end{array}$ & Dissatisfied & $\begin{array}{l}\text { Fairly } \\
\text { satisfied }\end{array}$ & Satisfied & $\begin{array}{l}\text { Completely } \\
\text { satisfied }\end{array}$ \\
\hline The ways nursing & - & 5.0 & 22.0 & 52 & 21 \\
\hline staff behaves the patient & - & 5.0 & 22.0 & 52 & 21 \\
\hline The nursing staff's mastery & - & 4.0 & 11.0 & 65 & 20 \\
\hline and experience & - & 4.0 & 11.0 & 65 & 20 \\
\hline Nurses constant monitoring & - & 5.0 & 6.0 & 70 & 19 \\
\hline of the patients & - & 5.0 & 6.0 & 70 & 19 \\
\hline The nurse assistant's services concerning & 3 & 11.0 & 40.0 & 39 & 7 \\
\hline the patient's individual needs & 3 & 11.0 & 40.0 & 39 & 7 \\
\hline Medicine's availability & - & 1.0 & 30.0 & 64 & 4 \\
\hline when need & - & 1.0 & 30.0 & 64 & 4 \\
\hline \multirow[t]{2}{*}{ Educating the patient } & 1 & 7.0 & 31.0 & 54 & 7 \\
\hline & 1 & 7.0 & 31.0 & 54 & 7 \\
\hline \multirow[t]{2}{*}{ Quick response to patients alarm } & 2 & 5.0 & 35.0 & 54 & 4 \\
\hline & 2 & 5.0 & 35.0 & 54 & 4 \\
\hline Giving necessary explanations before & - & 7.0 & 35.0 & 53 & 5 \\
\hline offering the services & - & 7.0 & 35.0 & 53 & 5 \\
\hline \multirow[t]{2}{*}{ Observing the patient's privacy } & 1 & 11.0 & 36.0 & 49 & 3 \\
\hline & 1 & 11.0 & 36.0 & 49 & 3 \\
\hline Nurses general treatment & - & 3.0 & 17.0 & 68 & 12 \\
\hline towards the patient & - & 3.0 & 17.0 & 68 & 12 \\
\hline Total means & 2 & 5.9 & 26.3 & $56 / 8$ & $10 / 2$ \\
\hline
\end{tabular}


Fereshteh Farzianpour et al. / American Journal of Applied Sciences, 10 (4): 344-352, 2013

Table 3. Absolute and relative frequency distribution concerning the degree of patient's satisfaction based on different hospital services (Laboratory and imaging staff)

\begin{tabular}{|c|c|c|c|c|c|}
\hline $\begin{array}{l}\text { Satisfaction status hospital services } \\
\text { C- Laboratory and imaging staff }\end{array}$ & $\begin{array}{l}\text { Completely } \\
\text { satisfied }\end{array}$ & Dissatisfied & $\begin{array}{l}\text { Fairly } \\
\text { satisfied }\end{array}$ & Satisfied & $\begin{array}{l}\text { Completely } \\
\text { dissatisfied }\end{array}$ \\
\hline The way laboratory & - & - & 9 & 30 & 2.0 \\
\hline personnel behave the patients & - & - & 9 & 30 & 2.0 \\
\hline The way imaging personnel & - & 3 & 6 & 26 & 7.0 \\
\hline behave the patients & - & 3 & 6 & 26 & 7.0 \\
\hline \multirow[t]{2}{*}{ Doing medical tests without delay } & - & 1 & 10 & 27 & 2.0 \\
\hline & - & 1 & 10 & 27 & 2.0 \\
\hline \multirow[t]{2}{*}{ Doing imaging services without delay } & - & 2 & 9 & 25 & 3.0 \\
\hline & - & 2 & 9 & 25 & 3.0 \\
\hline \multirow[t]{2}{*}{ Sampling skills in the lab } & - & - & 9 & 28 & 3.0 \\
\hline & - & - & 9 & 28 & 3.0 \\
\hline Total mean & - & 2 & $8 / 6$ & $27 / 2$ & 4.2 \\
\hline
\end{tabular}

Table 4. Absolute and relative frequency distribution concerning the degree of patient's satisfaction based on different hospital services (Services staff)

\begin{tabular}{|c|c|c|c|c|c|}
\hline $\begin{array}{l}\text { Satisfaction status } \\
\text { hospital services } \\
\text { D-Services staff }\end{array}$ & $\begin{array}{l}\text { Completely } \\
\text { dissatisfied }\end{array}$ & Dissatisfied & $\begin{array}{l}\text { Fairly } \\
\text { satisfied }\end{array}$ & Satisfied & $\begin{array}{l}\text { Completely } \\
\text { satisfied }\end{array}$ \\
\hline The way services personnel & 1 & 2 & 6.0 & 46 & 44.0 \\
\hline behave the patients & 1 & 2 & 6.0 & 46 & 44.0 \\
\hline The patient's & 1 & 9 & 17.0 & 51 & 22.0 \\
\hline room cleanliness & 1 & 9 & 17.0 & 51 & 22.0 \\
\hline The cleanliness & 1 & 20 & 26.0 & 49 & 4.0 \\
\hline of the toilets & 1 & 20 & 26.0 & 49 & 4.0 \\
\hline Cleaning the clothes, & 6 & 16 & 21.0 & 49 & 8.0 \\
\hline sheets and blankets & 6 & 16 & 21.0 & 49 & 8.0 \\
\hline Peace and silence & 2 & 12 & 29.0 & 50 & 7.0 \\
\hline in the ward & 2 & 12 & 29.0 & 50 & 7.0 \\
\hline \multirow[t]{2}{*}{ Patients facilities } & 11 & 30 & 38.0 & 20 & 1.0 \\
\hline & 11 & 30 & 38.0 & 20 & 1.0 \\
\hline Heating and cooling & 5 & 22 & 29.0 & 44 & -.0 \\
\hline status of the patient's room & 5 & 22 & 29.0 & 44 & -.0 \\
\hline \multirow[t]{2}{*}{ The way and quality of food } & 11 & 15 & 28.0 & 43 & 3.0 \\
\hline & 11 & 15 & 28.0 & 43 & 3.0 \\
\hline Facilities for the & 7 & 19 & 33.0 & 40 & 1.0 \\
\hline patient's attendant & 7 & 19 & 33.0 & 40 & 1.0 \\
\hline \multirow[t]{2}{*}{ Time of patients visit } & - & 2 & 13.0 & 78 & 7.0 \\
\hline & - & 2 & 13.0 & 78 & 7.0 \\
\hline 11 Total mean & 5 & $14 / 7$ & 17.3 & 47 & 10.7 \\
\hline
\end{tabular}

Table 5. Absolute and relative frequency distribution concerning the degree of patient's satisfaction based on different hospital services (discharge staff)

\begin{tabular}{lllllc}
\hline $\begin{array}{l}\text { Satisfaction status } \\
\text { Hospital services }\end{array}$ & $\begin{array}{c}\text { Completely } \\
\text { E-discharge staff }\end{array}$ & satisfied & Satisfied & $\begin{array}{l}\text { Fairly } \\
\text { satisfied }\end{array}$ & $\begin{array}{l}\text { Dissatisfied } \\
\text { Completely } \\
\text { dissatisfied }\end{array}$ \\
\hline The way discharge & 45 & 30 & 17 & 3 & - \\
personnel behave the patient & 45 & 30 & 17 & 3 & - \\
The length of the time the & 1 & 38 & 37 & 16 & 3 \\
patient should wait to be discharged observing & 1 & 38 & 37 & 16 & 3 \\
The patient's turn for discharge & - & 42 & 33 & 17 & 3 \\
& - & 42 & 33 & 17 & 3 \\
4Total mean & 23 & $36 / 6$ & 29 & 12 & 3 \\
\hline
\end{tabular}


Table 6. Patients' satisfaction concerning the hospital wards

\begin{tabular}{llll}
\hline Ward & High & Moderate & Low \\
\hline Women internal ward (10 people) & 20 & 80 & 0 \\
Men internal ward (10 people) & 40 & 60 & 0 \\
Women neurology ward (10 people) & 50 & 50 & 0 \\
Men neurology ward (10 people) & 40 & 60 & 0 \\
women orthopedics (10 people) & 50 & 50 & 0 \\
Men orthopedics (10 people) & 50 & 50 & 0 \\
Women surgical (10 people) & 60 & 40 & 0 \\
Men surgical (10 people) & 50 & 50 & 0 \\
Urology (10 people) & 60 & 40 & 0 \\
Transplant (10 people) & 90 & 10 & 0 \\
\hline
\end{tabular}

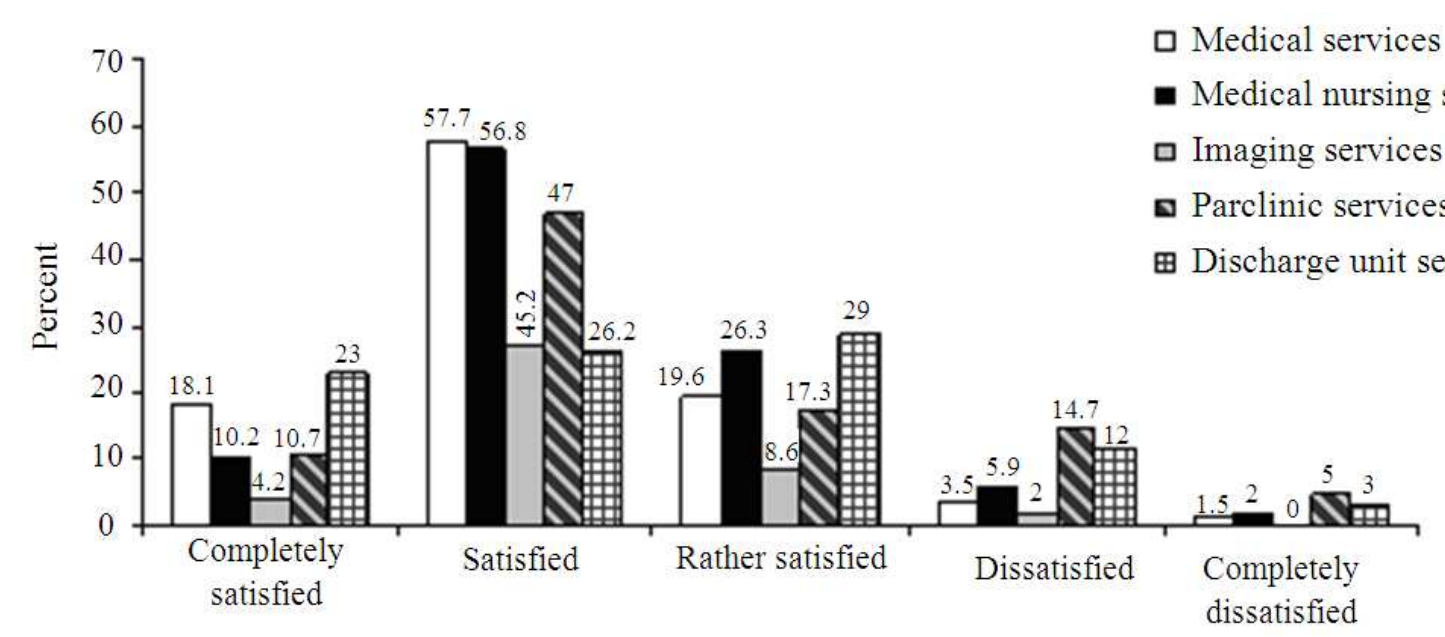

Fig. 1. The degree of patients' satisfaction with hospital services concerning medical, nursing and par clinical services

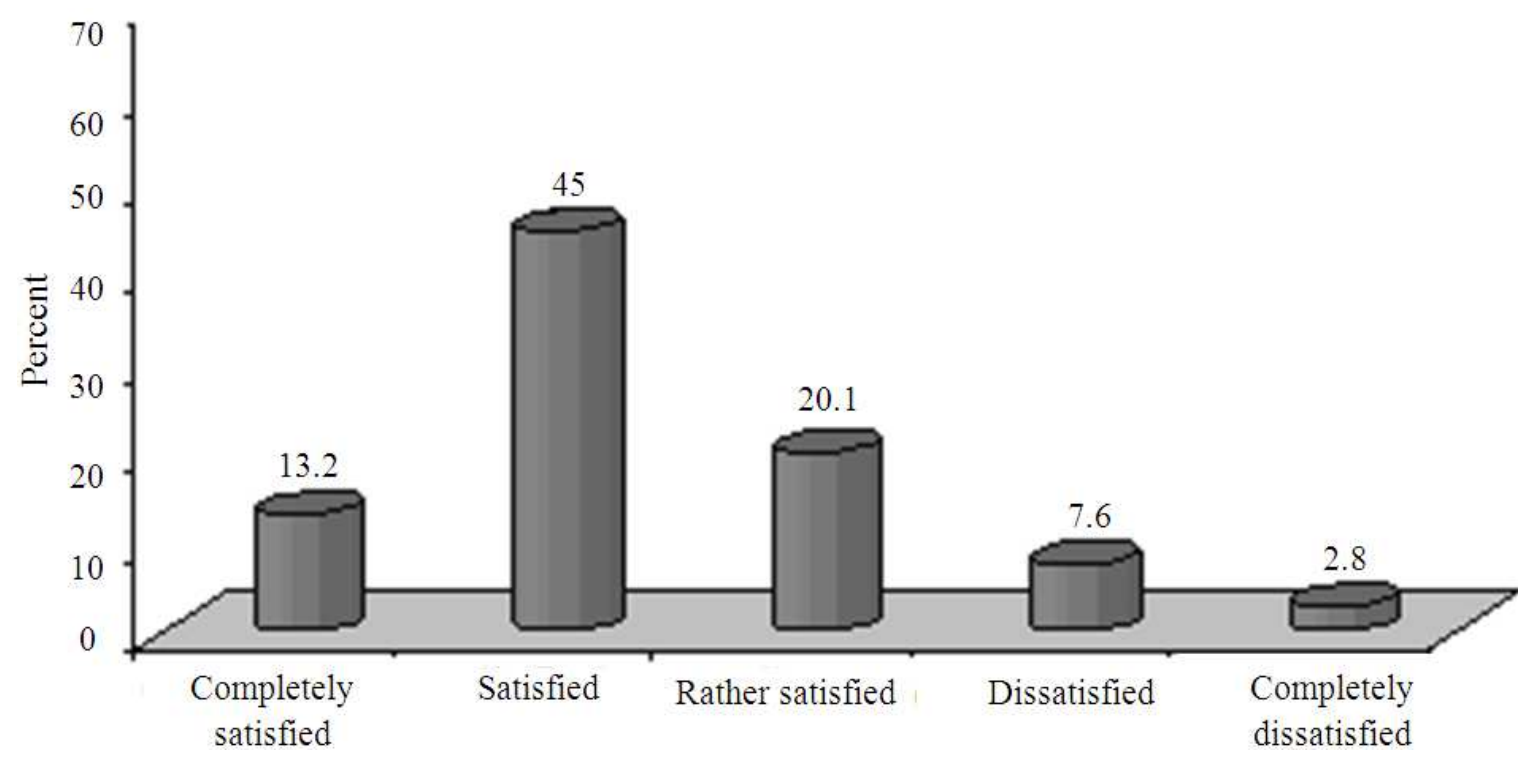

Fig. 2. The degree of Patients' general satisfaction with hospital services 
Concerning satisfaction with nursing staff treatment, the patients under twenty had the highest degree of satisfaction and the lowest degree was related to that between 20-30. Regarding satisfaction with service staff treatment, the patients aged between 40-50 and that between 20-30 had the highest and lowest degree of satisfaction respectively.

\section{DISCUSSION}

In the present study we investigated the difference in the various aspects of patient's relationship management based on patients' satisfaction in a teaching hospital. In this study a response rate of $75 \%$ was seen. In epidemiological studies a response rate of $80 \%$ has been proposed as a minimum. In studies on patients' satisfaction response rates reported range from 66 to $77 \%$ depending on the way data are collected. Awareness of the non-response rate is important, especially when some evidence suggests that satisfied patients are more likely to answer the questions than the dissatisfied ones (Stevens et al., 2006).

It should be mentioned that if getting information from the patients is done after they are dismissed from hospital; it might affect the rate at which they answer the questions. The study conducted by Kelefian in 1997 and the study by Rosenheck and Lam (1997) suggested 39.7 and $37 \%$ of the patients answered the questions respectively (Boyer et al., 2009).

Since medical and nursing care play a pivotal role in patients' recovery, they have attracted most of the patients attention and so play a significant part in their satisfaction. In the present study most of the patients were satisfied with hospital services (13.2\% quiet satisfied and $45 \%$ rather satisfied). This result indicates correct patient relationship management and meeting their care needs. The highest degree of patients' satisfaction was with clinical services (medical and nursing). In the study conducted by Farzianpour et al. (2011a). The percentage of patients' satisfaction with nursing services, medical care reception, discharge were $79.5,83.881$ and $70.8 \%$ respectively. Patients' general satisfaction with hospital services showed a high percentage (87\%) (Farzianpour et al., 2011b).

Another study suggested that the degree of patients' satisfaction with reception unit nursing care and medical care was higher than that with other units. In addition the correlation coefficient between hospital sectors in patient wards was a little more than outpatient ones (Hekkert et al., 2009).
Eytan et al. (2004) showed that the patients' degree of satisfaction, in Geneva University-affiliated hospitals with the clinic, medical care, environment and hospital facilities, nutrition and Laundry were 53.3, 53.7, 56.6 and $50 \%$ respectively. The results of these studies are in line with the findings of the present study. Farzianpour et al. (2011d) in a study showed $72 \%$ of the patients hospitalized in public hospitals were satisfied with hospital general services. The hospital's defects negative points from their point of view were: Beds' wear, wards' crowdedness, unsuitable welfare facilities, unsuitable W.C.S, doctors' delay, shortage of technical and diagnostic equipment (Farzianpour et al., 2012). The results of a study conducted by Joulaei and Azam (2008) showed the rate of satisfaction with nursing services and that of general satisfaction with hospital's services were 39.7 and $36 \%$ respectively. This result is different from those of other studies. Considering nursing services the accessibility of nurses when needed, the way nursing staff treat the patients, delivering on-time services and skillfully providing enjoyed the highest rate of patient's satisfaction (Joulaei and Azam, 2008).

In this study the patient were asked if they intended to choose the hospital again. The results showed that $57 \%$ would choose the hospital and $14 \%$ another medical center. Considering history of hospitalization the results showed $62 \%$ didn't have history of hospitalization $38 \%$ had history of hospitalization ( $\operatorname{Rad}, 2007)$ Since having frequent clients and losing them is financially important for hospitals, through careful planning and improving the quality of services they can maintain their clients and so their share in the market. The results of another study showed that rate of patient's general satisfaction, desire for choosing the hospital again and recommending it to others was 85, 92 and $89 \%$ respectively (Farzianpour et al., 2011d).

The results of still another study indicated that only $45.3 \%$ of the patients recommended the hospital to others (Rabie and Shahid, 2007). In the present study there was a significant relationship between patient's satisfaction with the way nursing and services staff treat them and the patient's age. There was also a significant relationship between the way paraclinic and this charge staff treats them and the kind of patient's medical insurance. There was no significant relation between patient's satisfactions and the other factors. Another study showed that there is a significant statistical relation between patient's satisfactions and the level of their education income and accessibility of the hospital, but there was no significant relationship between patient's satisfactions and their age, sex, marital status, the place 
where they live and their job (Rabie and Shahid, 2007). Another study showed that in public hospitals there was a significant statistical relationship between the level of patient's education and the degree of their satisfaction with nursing services in that the higher the level of education, the more satisfied the patients (Joulaei and Azam, 2008). The results of study conducted by Rad (2007) showed that there was a significant relationship between the degree of patient's satisfactions and their age, sex level of education, marital status and hospitalization length ( $\mathrm{Rad}, 2007)$. It should be noted that different factors affect patient's satisfactions, including diagnostic, treatment and care services, the length of the time they wait to receive services, the need for receiving enough information and explanation, the doctors' characteristics, patient's individual characteristics such as age and sex. Another study suggested that the degree of satisfaction with hospital services is more considerable in women and younger people (Rahmqvist, 2001). The results of other studies unlike the above mentioned studies indicate that the degree of satisfaction in older people is higher (Rahmqvist, 2001). Therefore, concerning factors such as age, marital status and sex, the results are not the same in studies on client relationship management, senior managers' innovation, the size of the organization and the staff's ability also affect the way they communicate the patients and so their satisfaction with the organization (Hung et al., 2010).

\section{CONCLUSION}

Considering the results of the study different factors including personal characteristics of patients such as age, sex and marital status, characteristics of services providers, conditions and environment in which the services are provided can affect patient's satisfaction. Therefore, to increase the degree of patient's satisfaction with the hospital's services, it is necessary to improve all hospital's services including clinical, service, diagnostic and management. It is also necessary to provide a model to improve patient's satisfaction based on the process of patient relationship management in teaching hospitals. To improve the process of patient relationship management in hospitals, the following are suggested:

- Accurate and suitable planning to use patient's opinion

- Using the experiences of the hospitals which have been successful in patient relationship management determining the reasons for patient's dissatisfaction, esp. considering the way they are treated (behaved towards) and trying to meet their dissatisfaction

- Praising the staff based on the degree of patient's satisfaction with ways they behave towards them

- Reflecting patient's satisfaction or dissatisfaction with the way the personnel of each unit treat them to different medical, paramedical group and also financial and administrative personnel

- Making the patients aware of patient's rights charter to have a better understanding of their rights

- Improving the level of awareness, attitude and communication skills of the hospital personnel, esp. medical and nursing staff in order to observe the patient's rights

- Encouraging managements to do continuous monitoring through rounds and to visit other hospitals, the ones in the country and those which are abroad, to acquire experience to improve the quality of patient communication and the degree of their satisfaction

- Continues monitoring of the personnel of hospital units including service, nutrition, laundry concerning the way the personnel behave towards the patients in order to make a plan to correct and improve processes and quality of patient communication

- Designing the system of patient suggestions

- Educating the personnel, including medical and paramedical, concerning the chart of the organization

- Educating, including personal regarding improving communication skills and humanities

\section{ACKNOWLEDGEMENT}

We thank the management's teams of the hospitals for allowing access to their organizations and also those members of the hospitals who kindly provided us with the data needed for the study.

\section{REFERENCES}

Anastasios, M., E.D.E. Papathanassoglou and C. Lemonidou, 2004. Evaluation of patient satisfaction with nursing care: Quantitative or qualitative approach? Int. J. Nurs. Stud., 41: 355-367. DOI: 10.1016/j.ijnurstu.2003.10.006

Boyer, L., K. Baumstarck-Barrau, N. Cano, X. Zendjidjian and R. Belzeaux, 2009. Assessment of psychiatric inpatient satisfaction: A systematic review of self-reported instruments. Eur. Psychiatry, 24: 540-549. PMID: 19699617 
Eytan, A., L. Bovet, M. Gex-Fabry, C. Alberque and F. Ferrero, 2004. Patients' satisfaction with hospitalization in a mixed psychiatric and somatic care unit. Eur. Psychiatry, 19: 499-501. PMID: 15589710

Farzianpour, F. and L. Godarzi, 2010. Evaluation of Customer Relationship Management (CRM) in a teaching hospital affiliated with Tehran University of Medical Sciences. Tehran University.

Farzianpour, F., A.R. Fouroshani, R.G. Vahidi, M. Arab and A. Mohamadi, 2011a. Investigating the relationship between organizational social capital and service quality in teaching hospitals. Am. J. Econ. Bus. Admin., 3: 425-429. DOI: 10.3844/ajebasp.2011.425.429

Farzianpour, F., A.R. Fouroshani, R.G. Vahidi, M. Arab and A. Mohamadi, 2011d. Investigating the relationship between organizational social capital and service quality in teaching hospitals. Am. J. Econ. Bus. Admin. 3: 425-429. DOI: 10.3844/ajebasp.2011.425.429

Farzianpour, F., M. Arab, S. Amoozagar, A.R. Fouroshani and A. Rashidian et al., $2011 \mathrm{~b}$. Evaluation of international standards of Quality improvement and Patient Safety (QPS) in hospitals of Tehran University of Medical Sciences (TUMS) from the managers' point of view. World Applied Sci. J., 15: 647-653.

Farzianpour, F., S. Aghababa, B. Delgoshaei and M. Haghgoo, 2011c. Performance evaluation a teaching hospital affiliated to Tehran University of medical sciences based on baldrige excellence model. Am. J. Econ. Bus. Admin., 3: 277-281. DOI: 10.3844/ajebasp.2011.272.276

Farzianpour, F., S. Hosseini, T. Amali, S. Hosseini and S.S.H. Hosseini, 2012. The evaluation of relative efficiency of teaching hospitals. Am. J. Applied Sci., 9: 392-398. DOI: 10.3844/ajassp.2012.392.398

Hekkert, K.D., S. Cihangir, S.M. Kleefstra, B.V.D. Berg and R.B. Kool, 2009. Patient satisfaction revisited: A multilevel approach. Soc. Sci. Med., 69: 68-75. DOI: $10.1016 /$ j.socscimed.2009.04.016

Hung, S.Y., W.H. Hung, C.A. Tsai and S.C. Jiang, 2010. Critical factors of hospital adoption on CRM system: Organizational and information system perspectives. Decision Support Syst., 48: 592-603. DOI: $10.1016 /$ j.dss.2009.11.009
Jangland, E., L. Gunningberg and M. Carlsson, 2009. Patients' and relatives' complaints about encounters and communication in health care: Evidence for quality improvement. Patient Educ. Counsel., 75: 199-204. DOI: 10.1016/j.pec.2008.10.007

Joulaei, S. and G. Azam, 2008. Patient satisfaction with nursing care in hospitals in the country. Nurs. Res., 2: 44-37.

Mpinga, E.K. and P. Chastonay, 2011. Satisfaction of patients: A right to health indicator? Health Policy, 100: 144-150. DOI: 10.1016/j.healthpol.2010.11.001

Rabie, M.A.S. and A. Shahid, 2007. Satisfaction of patients in public hospitals under the Medical Sciences, Hamedan and its influencing factors. Monitoring, 5: 279-271.

Rad, M.A., 2007. Assessment of patient satisfaction of hospital services in Razi hospital of Qazvin. Health Inform. Manage., 1: 32-28.

Rahmqvist, M., 2001. Patient satisfaction in relation to age, health status and other background factors: A model for comparisons of care units. Int. J. Qual. Health Care, 13: 385-390. PMID: 11669566

Rosenheck, R. and J. Lam, 1997. 'Homeless mentally ill clients' and providers' perceptions of service needs and clients' use of services. Psychiatr. Serv., 48: 381-386. PMID: 9057242

Saila, T., E. Mattila, M. Kaila, P. Aalto and M. Kaunonen, 2008. Measuring patient assessments of the quality of outpatient care: A systematic review. J. Eval. Clin. Pract., 14: 148-154. PMID: 18211659

Schoenfelder, T., J. Klewer and J. Kugler, 2010. Factors associated with patient satisfaction in surgery: The role of patients' perceptions of received care, visit characteristics and demographic variables. J. Surgical Res., 164: 53-59. PMID: 20863521

Sherlaw-Johnson, C., P. Datta and M. McCarthy, 2008. Hospital differences in patient satisfaction with care for breast, colorectal, lung and prostate cancers. Eur. J. Cancer, 44: 1559-1565. PMID: 18430563

Stevens, M., I.H. Reininga, N.A. Boss and J.R.V. Horn, 2006. Patient satisfaction at and after discharge. Effect of a time lag. Patient Educ. Counsel., 60: 241245. PMID: 16253466 